\title{
Usulan Rancangan Perbaikan Pengelolaan Laboratorium Berdasarkan Hasil Gap Analysis dengan ISO 9001:2015 pada Laboratorium Teknik Industri Universitas Islam Bandung
}

\author{
Muhammad Abduh Nggole", Yan Orgianus \\ Prodi Teknik Industri, Fakultas Teknik, Universitas Islam Bandung,Indonesia. \\ *muhammadabduhnggole@gmail.com, yan.organius@unisba.ac.id
}

\begin{abstract}
Laboratories in the context of education basically have a function as a supporter of the learning process and research carried out by students and lecturers. The learning process carried out in the laboratory is to provide practical learning experiences for students to recognize the tools and materials using them directly and apply the theory gained during class. The activities carried out can run well if they can be balanced with the quality of services and laboratory management. The method used is ISO 9001:2015 which serves to collect identification data for laboratory adjustments. In addition, the method used, namely the maturity level of the management process, is used to determine how well the laboratory management has been carried out at LTI UNISBA, while the gap analysis method is used to provide suggestions for laboratory management so that the gap between what is achieved and what is expected can be minimized. The results of the evaluation with ISO 9001:2015 for the Laboratory of Work Design Analysis and Ergonomics are worth 1.77, the Quality Management Laboratory is worth 1.75, the Information and Decision Systems Laboratory is worth 1.76, and the Production Systems Laboratory is worth 1.74. The overall average value of UNISBA's LTI is 1.76, which means that UNISBA's LTI for the quality management system is at level 1.
\end{abstract}

Keywords: ISO 9001:2015, Laboratory, Level Maturity.

\begin{abstract}
Abstrak.Laboratorium dalam konteks pendidikan pada dasarnya mempunyai fungsi sebagai penunjang proses pembelajaran dan penelitian yang dilakukan oleh mahasiswa dan dosen. Proses pembelajaran yang dilakukan di laboratorium yaitu memberikan pengalaman praktek belajar kepada mahasiswa untuk mengenali alat dan bahan dalam menggunakannya secara langsung serta menerapkan teori yang didapat selama didalam kelas. Kegiatan yang dilakukan tersebut dapat berjalan dengan baik apabila dapat diimbangi dengan mutu dari pelayanan dan pengelolaan laboratorium. Adapun metode yang digunakan yaitu ISO 9001:2015 yang berfungsi untuk pengumpulan data identifikasi penyesuaian terhadap laboratorium. Selain itu, metode yang digunakan yaitu tingkat kematangan proses pengelolaan digunakan untuk mengetahui seberapa baik pengelolaan laboratorium yang telah dilakukan pada LTI UNISBA sedangkan metode analisis kesenjangan digunakan untuk memberikan usulan pengelolaan laboratorium agar kesenjangan antara yang dicapai dan yang diharapkan dapat diminimalkan.Adapun hasil evaluasi dengan ISO 9001:2015 untuk Laboratorium Analisis Perancangan Kerja dan Ergonomi bernilai 1.77, Laboratorium Manajemen Kualitas bernilai 1.75, Laboratorium Sistem Informasi dan Keputusan bernilai 1.76, dan Laboratorium Sistem Produksi bernilai 1.74. Nilai rata rata keseluruhan LTI UNISBA bernilai 1,76 yang berarti LTI UNISBA untuk sistem manajemen mutu masuk pada level 1.
\end{abstract}

Kata Kunci: ISO 9001:2015, Laboratorium, Tingkat Kematangan. 


\section{A. Pendahuluan}

Peningkatan mutu baik dalam meningkatkan pelayanan dan pengelolaan pada sebuah organisasi atau lembaga termasuk laboratorium yaitu harus memiliki standar yang mengacu pada standar yang sudah ditetapkan. Tujuan dari hal ini agar dapat menjadikan organisasi atau lembaga termasuk laboratorium memiliki sistem pengelolaan dan mutu yang berkualitas. Mutu merupakan suatu indikator penting dalam mewujudkan kesuksesan baik dari segi pelayanan dan pengelolaan agar dapat menghasilkan produk atau jasa sehingga dapat memenuhi harapan dan menjaga keunggulannya .

International Standard Organization mengatakan bahwa laboratorium atau organisasinya merupakan suatu kesatuan yang memiliki sistem manajemen mutu dan teknis yang memadai, dan memiliki sumber daya manusia yang cukup pada posisi yang sesuai dengan kemampuan. Hal ini menjelaskan bahwa laboratorium harus menetapkan, menerapkan, dan memelihara sistem manajemen mutu yang sesuai dengan lingkup kegiatannya Sehingga sistem manajemen mutu dapat terwujud dan terkelola dengan baik dengan benar. Teknik Industri merupakan salah satu program studi dalam fakultas Teknik yang sudah terverifikasi dengan menggunakan ISO 9001:2015. Program studi ini memiliki 4 laboratorium yaitu Laboratorium Sistem Informasi dan Keputusan, Laboratorium Analisis Perancangan Kerja dan Ergonomi, Laboratorium Manajemen Kualitas, dan Laboratorium Sistem Produksi. Namun dalam prakteknya, 4 laboratorium tersebut belum menyesuaikan standar yang ada dan ISO 9001:2015 dalam penjaminan mutunya sehingga dibutuhkan penerapannya agar laboratorium tersebut dapat meningkatkan mutu baik dari sisi pelayanan dan pengelolaannya serta sejalan dengan kebijakan Badan Penjaminan Mutu .

Berdasarkan latar belakang yang telah diuraikan maka tujuan dalam penelitian ini diuraikan dalam pokok-pokok sebagai berikut:

1. Untuk mengetahui sistem manajemen mutu saat ini di Laboratorium Teknik Industri Universitas Islam Bandung.

2. Mengetahui hasil evaluasi manajemen mutu dengan menggunakan ISO 9001:2015 di Laboratorium Teknik Industri Universitas Islam Bandung.

3. Memberikan usulan rekomendasi rancangan sistem pengelolaan dengan mempertimbangkan hasil evaluasi sistem manajemen mutu di Laboratorium Teknik Industri Universitas Islam Bandung.

\section{B. Metodologi}

Metodologi yang dilakukan dalam penelitian ini terdiri dari kerangka berpikir dan tahapan pemecahan masalah. Kerangka berpikir ini menjelaskan tentang kondisi awal laboratorium hingga masalah yang diakibatkan oleh kondisi awal tersebut, kemudian lanjut ke tindakan perbaikan dimana tindakan yang membantu suatu laboratorium dalam memperbaiki kondisi sebelumnya, dan terakhir yaitu kondisi akhir dimana dugaan setelah melakukan tindakan yang diberikan pada laboratorium. Selanjutnya dalam tahapan pemecahan masalah terdapat 5 tahapan yang diakukan yaitu tahapan identifikasi dan penelitian awal, tahapan pengumpulan data, tahapan pengolahan data, tahapan analisis dan pembahasan, dan tahapan kesimpulan dan saran. Adapun metode yang digunakan yaitu ISO 9001:2015, Tingkat Kematangan (Maturity Level) dan Analisis Kesenjangan (Gap Analysis).

Menurut Philips (2015) menjelaskan ISO 9001: 2015 dapat meningkatkan kualitas layanan dan produk dengan memberikan panduan dan alat kepada organisasi atau institusi, termasuk laboratorium, yang ingin memastikan bahwa layanan atau produk yang mereka tawarkan mencakup atau memenuhi persyaratan pengguna. Standar yang digunakan didasarkan pada sejumlah prinsip dalam sistem manajemen mutu (quality management system). Selain itu, standar yang digunakan mencakup pendekatan proses, dampak pada manajemen motivasi dan dukungan, fokus pelanggan yang kuat dan peningkatan berkelanjutan.Manfaat menggunakan ISO 9001: 2015 baik di organisasi maupun institusi, termasuk laboratorium, serupa dengan salah satu tujuan utama sistem manajemen mutu yang bertindak sebagai alat pencegahan. Dalam ISO 
9001:2015 terdaapat 10 klausul yang termasuk ke dalam ISO 9001:2015 yaitu 1.) ruang lingkup, 2.) acuan normatif, 3.) istilah dan definisi, 4.) konteks organisasi, 5.) kepemimpinan, 6.) perencanaan, 7.) dukungan, 8.) operasional, 9.) evaluasi kinerja, dan 10.) peningkatan (Abuhav, 2017).

Tingkat kematangan (maturity level) suatu metode evaluasi sistem yang menggambarkan kondisi perusahaan saat ini. Metode ini digunakan untuk menilai sedemikian rupa sehingga suatu organisasi atau lembaga dapat menilai dirinya sendiri dari tidak ada (non existent) ke dioptimalkan (optimized). Metode yang digunakan ini penilaiannya dimulai dari 0 sampai 5 . Pendekatan yang digunakan pada metode ini didasarkan pada kematangan yang ditentukan oleh Software Engineering Institute (SEI). Tujuannya adalah untuk mengidentifikasi di mana letak permasalahan dan bagaimana memprioritaskan perbaikan (ITGI, 2007). Berikut ini merupakan tingkat kematangan dan keterangan yang akan ditampilkan pada Tabel 1.

Tabel 1 Tingkat Kematangan dan Kematangan

\begin{tabular}{|c|c|c|}
\hline $\begin{array}{c}\text { Tingka } \\
\mathbf{t}\end{array}$ & Kematangan & Keterangan \\
\hline 0 & $\begin{array}{c}\text { Tidak Ada } \\
\text { (Non Existent) }\end{array}$ & $\begin{array}{l}\text { Tidak ada proses sistem manajemen mutu yang dapat diidentifikasi. } \\
\text { Laboratorium belum menyadari bahwa adanya masalah yang akan } \\
\text { dihadapi. }\end{array}$ \\
\hline 1 & $\begin{array}{c}\text { Awal } \\
\text { (Initial) }\end{array}$ & $\begin{array}{l}\text { Laboratorium sudah mulai mengenali proses sistem manajemen mutu di } \\
\text { laboratoriumnya, tidak terorganisasi, dilakukan secara individu dan } \\
\text { belum ada standarisasi. Terdapat bukti bahwa laboratorium telah } \\
\text { menyadari adanya masalah yang akan dihadapi. Pendekatan yang } \\
\text { dilakukan secara keseluruhan belum terorganisasi. }\end{array}$ \\
\hline 2 & $\begin{array}{l}\text { Dapat diulang tetapi } \\
\text { Intuitif } \\
\text { (Repeatable but } \\
\text { Intuitive) }\end{array}$ & $\begin{array}{l}\text { Laboratorium sudah mulai memiliki prosedur dalam proses sistem } \\
\text { manajemen mutu tetapi tidak ada pelatihan dan komunikasi formal } \\
\text { tentang prosedur tersebut. }\end{array}$ \\
\hline 3 & $\begin{array}{l}\text { Proses yang } \\
\text { ditentukan } \\
\text { (Defined Process) }\end{array}$ & $\begin{array}{l}\text { Prosedur di laboratorium sudah terdokumentasi, distandarisasi dan } \\
\text { dikomunikasikan tetapi implementasi masih tergantung laboratorium } \\
\text { apakah mau mengikuti prosedur tersebut atau tidak. Prosedur yang } \\
\text { dibuat hanya merupakan formalisasi kegiatan yang sudah ada }\end{array}$ \\
\hline 4 & $\begin{array}{l}\text { Terukur dan } \\
\text { Terkelola } \\
\text { (Measurable and } \\
\text { Managed) }\end{array}$ & $\begin{array}{l}\text { Laboratorium dapat memonitor dan mengukur prosedur yang ada } \\
\text { sehingga mudah diperbaiki apabila terjadi penyimpangan. Proses sistem } \\
\text { manajemen mutu sudah berjalan dengan baik dan konstan. }\end{array}$ \\
\hline 5 & $\begin{array}{l}\text { Dioptimalkan } \\
\text { (Optimized) }\end{array}$ & $\begin{array}{l}\text { Proses sistem manajemen mutu sudah mencapai pelaksanaan terbaik } \\
\text { (best practice) melalui perbaikan yang dilakukan secara terus menerus }\end{array}$ \\
\hline
\end{tabular}

Sumber: ITGI (2007)

Menurut Tjiptono (1997) dalam Hamta (2014) Untuk mengetahui bahwa terdapat kesenjangan (gap) untuk faktor yang telah didapatkan yaitu dengan menggunakan rumus Kesenjangan = Ekspektasi - Persepsi. Semakin besar kesenjangan, maka semakin besar pula jarak antara apa yang diinginkan konsumen dan apa yang sebenarnya mereka dapatkan.

\section{Hasil dan Pembahasan}

Pengumpulan data dilakukan pada laboratorium Teknik Industri Universitas Islam Bandung. Objek penelitian pada laboratorium adalah seluruh laboratorium Teknik Industri Universitas Islam Bandung (LTI UNISBA) diantaranya Laboratorium Sistem Informasi dan Keputusan, Laboratorium Analisis Perancangan Kerja dan Ergonomi, Laboratorium Manajemen Kualitas, dan Laboratorium Sistem Produksi. Data yang dibutuhkan yaitu 1.) Gambaran umum Laboratorium, 2.) Dokumen yang terdapat di Laboratorium, 3.) Hasil identifikasi kesesuaian dengan ISO 9001:2015.

Setelah dilakukannya pengumpulan data, kemudia yaitu memberikan kriteria pada hasil identifikasi kesesuaian dengan menggunakan ISO 9001:2015. Berikut ini penentuan kirteria identfikasi penyesuaian pada setiap klausul ISO 9001:2015 yang akan ditunjukkan pada Tabel 2.Berdasarkan hasil yang telah dilakukan identifikasi penyesuaian dengan menggunakan ISO 
9001:2015 dan sudah di rata-ratakan dapat ditampilkan pada Tabel 4. Kemudian data yang digunakan dalam pengolahan data ini merupakan data dari hasil identifikasi penyesuaian ISO 9001:2015. Adapun pengolahan data yang dilakukan yaitu menentukan indeks tingkat kematangan (maturity level) dan menentukan tingkat kematangan (maturity level) serta memberikan kesimpulan. Dalam menentukan nilai dari level maturity untuk setiap klausul yaitu dengan menggunakan rumus (Widia, 2012):

$$
\text { Indeks Tingkat Kematangan }(C)=\frac{\text { Jumlah nilai jawaban }(A)}{\text { Jumlah pertanyaan }(B)}
$$

Tabel 2 Kriteria Identifikasi Penyesuaian pada Setiap Klausul ISO 9001:2015

\begin{tabular}{|c|c|}
\hline Kriteria & Keterangan \\
\hline Buruk sekali & $\begin{array}{ll} & \text { Tidak adanya penerapan di lapangan } \\
. & \text { Tidak adanya sistem manajemen mutu } \\
\text {. } & \text { Tidak adanya dokumentasi }\end{array}$ \\
\hline Buruk & $\begin{array}{l}\text { Penerapan tidak dilakukan secara penuh di lapangan }( \pm 21-40 \%) \\
\text { Tidak adanya sistem manajemen mutu } \\
\text { Sudah adanya dokumentasi }\end{array}$ \\
\hline Sedang & $\begin{array}{l}\text { Penerapan tidak dilakukan secara penuh di lapangan }( \pm 41-60 \%) \\
\text { Sudah adanya sistem manajemen mutu } \\
\text { Sudah adanya dokumentasi }\end{array}$ \\
\hline Baik & $\begin{array}{l}\text { Penerapan tidak dilakukan secara penuh di lapangan }( \pm 61-80 \%) \\
\text { Sudah adanya sistem manajemen mutu } \\
\text { Sudah adanya dokumentasi }\end{array}$ \\
\hline Baik Sekali & $\begin{array}{l}\text { Penerapan dilakukan secara penuh di lapangan }( \pm 81-100 \%) \\
\text { Sudah adanya sistem manajemen mutu } \\
\text { Sudah adanya dokumentasi }\end{array}$ \\
\hline
\end{tabular}

Sumber: Anggraeni (2017)

Berdasarkan hasil perhitungan rata rata indeks tingkat kematangan untuk keseluruhan Laboratorium Teknik Industri UNISBA dapat ditampilkan pada Tabel 3.

Tabel 3 Hasil Perhitungan Rata Rata Indeks Tingkat Kematangan Untuk Keseluruhan Laboratorium Teknik Industri UNISBA

\begin{tabular}{|c|l|c|c|c|c|c|c|}
\hline \multicolumn{2}{|c|}{ Klausul } & APK & ManKul & LSIK & SisProd & $\begin{array}{c}\text { Rata } \\
\text { Rata }\end{array}$ & $\begin{array}{c}\text { Tingkat } \\
\text { Kematangan }\end{array}$ \\
\hline 4 & Konteks Organisasi & 1.85 & 1.85 & 1.77 & 1.85 & 1.83 & Awal \\
\hline 5 & Kepemimpinan & 2.00 & 2.00 & 2.00 & 2.00 & 2.00 & Awal \\
\hline 6 & Perencanaan & 1.80 & 1.60 & 1.80 & 1.80 & 1.75 & Awal \\
\hline 7 & Dukungan & 1.84 & 1.80 & 1.84 & 1.64 & 1.78 & Awal \\
\hline 8 & Operasional & 1.70 & 1.70 & 1.70 & 1.70 & 1.70 & Awal \\
\hline 9 & Evaluasi Kinerja & 1.50 & 1.50 & 1.50 & 1.50 & 1.50 & Tidak Ada \\
\hline 1 & Perbaikan & 1.75 & 1.75 & 1.75 & 1.75 & 1.75 & Awal \\
\hline 0 & Rata - Rata & $\mathbf{1 . 7 8}$ & $\mathbf{1 . 7 4}$ & $\mathbf{1 . 7 7}$ & $\mathbf{1 . 7 5}$ & $\mathbf{1 . 7 6}$ & Awal \\
\hline
\end{tabular}

Menghitung kesenjangan antara hasil yang dicapai dengan hasil yang diharapkan yaitu melalui perhitungan persepsi dikurangi dengan ekspektasi. Untuk persepso menggunakan tingkat kematangan sekarang dan ekspektasi menggunakan tingkat kematangan harapan. Target yang ingin diharapkan pada LTI UNISBA ini yaitu pada level 4 (terukur dan terkelola) dikarenakan laboratorium sebelumnya belum memiliki standar yang sesuai dengan sistem manajemen mutu 
ISO 9001:2015 sehingga laboratorium tersebut harus masuk pada tingkat yang terukur dan terkelola terlebih dahulu sebelum memasuki tingkat dioptimalkan.Berikut ini merupakan hasil perhitungan kesenjangan untuk keseluruhan LTI UNISBA yang dapat dilihat pada Tabel 5.

Tabel 4 Hasil Rata Rata untuk Keseluruhan Laboratorium Teknik Industri UNISBA

\begin{tabular}{|c|c|c|c|c|c|c|c|c|}
\hline \multicolumn{2}{|c|}{ Klausul } & \multirow{2}{*}{$\begin{array}{c}\text { Syarat } \\
4.1\end{array}$} & \multirow{2}{*}{$\begin{array}{c}\text { APK } \\
1.5\end{array}$} & \multirow{2}{*}{$\begin{array}{c}\begin{array}{l}\text { ManKu } \\
\text { l }\end{array} \\
1.5\end{array}$} & \multirow{2}{*}{$\begin{array}{c}\text { LSIK } \\
1.5\end{array}$} & \multirow{2}{*}{$\begin{array}{c}\begin{array}{c}\text { SisPro } \\
\text { d }\end{array} \\
1.5\end{array}$} & \multirow{2}{*}{\begin{tabular}{c|}
$\begin{array}{c}\text { Rata } \\
\text { Rata }\end{array}$ \\
1.5
\end{tabular}} & \multirow{2}{*}{$\begin{array}{c}\begin{array}{c}\text { Kategori } \\
\text { Maturity }\end{array} \\
\text { Buruk } \\
\text { Sekali }\end{array}$} \\
\hline & \multirow{4}{*}{$\begin{array}{l}\text { Konteks } \\
\text { Organisasi }\end{array}$} & & & & & & & \\
\hline 4 & & 4.2 & 2 & 2 & 2 & 2 & 2 & Buruk \\
\hline & & 4.3 & 2 & 2 & 2 & 2 & 2 & Buruk \\
\hline & & 4.4 & 1.88 & 1.88 & 1.75 & 1.88 & 1.84 & Buruk \\
\hline \multirow{3}{*}{5} & \multirow{3}{*}{$\underset{n}{\text { Kepemimpina }}$} & 5.1 & 2 & 2 & 2 & 2 & 2 & Buruk \\
\hline & & 5.2 & 2 & 2 & 2 & 2 & 2 & Buruk \\
\hline & & 5.3 & 2 & 2 & 2 & 2 & 2 & Buruk \\
\hline \multirow{3}{*}{6} & \multirow{3}{*}{ Perencanaan } & 6.1 & 1.5 & 1.5 & 1.5 & 1.5 & 1.5 & $\begin{array}{l}\text { Buruk } \\
\text { Sekali }\end{array}$ \\
\hline & & 6.2 & 2 & 1.5 & 2 & 2 & 1.88 & Buruk \\
\hline & & 6.3 & 2 & 2 & 2 & 2 & 2 & Buruk \\
\hline \multirow{5}{*}{7} & \multirow{5}{*}{ Dukungan } & 7.1 & 1.79 & 1.64 & 1.93 & 1.71 & 1.77 & $\begin{array}{l}\text { Buruk } \\
\text { Sekali }\end{array}$ \\
\hline & & 7.2 & 2 & 2 & 1.5 & 1 & 1.63 & $\begin{array}{l}\text { Buruk } \\
\text { Sekali }\end{array}$ \\
\hline & & 7.3 & 2 & 2 & 2 & 2 & 2 & Buruk \\
\hline & & 7.4 & 2 & 2 & 2 & 2 & 2 & Buruk \\
\hline & & 7.5 & 1.8 & 2 & 1.8 & 1.8 & 1.85 & Buruk \\
\hline \multirow{7}{*}{8} & \multirow{7}{*}{ Operasional } & 8.1 & 2 & 2 & 2 & 2 & 2 & Buruk \\
\hline & & 8.2 & 2 & 2 & 2 & 2 & 2 & Buruk \\
\hline & & 8.3 & 1.93 & 1.93 & 1.87 & 1.93 & 1.92 & Buruk \\
\hline & & 8.4 & 1.43 & 1.43 & 1.43 & 1.43 & 1.43 & $\begin{array}{l}\text { Buruk } \\
\text { Sekali }\end{array}$ \\
\hline & & 8.5 & 1.17 & 1.17 & 1.33 & 1.17 & 1.21 & $\begin{array}{l}\text { Buruk } \\
\text { Sekali }\end{array}$ \\
\hline & & 8.6 & 2 & 2 & 2 & 2 & 2 & Buruk \\
\hline & & 8.7 & 1 & 1 & 1 & 1 & 1 & $\begin{array}{l}\text { Buruk } \\
\text { Sekali }\end{array}$ \\
\hline \multirow{3}{*}{9} & \multirow{3}{*}{$\begin{array}{l}\text { Evaluasi } \\
\text { Kinerja }\end{array}$} & 9.1 & 1 & 1 & 1 & 1 & 1 & $\begin{array}{l}\text { Buruk } \\
\text { Sekali }\end{array}$ \\
\hline & & 9.2 & 1.5 & 1.5 & 1.5 & 1.5 & 1.5 & $\begin{array}{l}\text { Buruk } \\
\text { Sekali }\end{array}$ \\
\hline & & 9.3 & 2 & 2 & 2 & 2 & 2 & Buruk \\
\hline \multirow{3}{*}{10} & \multirow{3}{*}{ Perbaikan } & 10.1 & 2 & 2 & 2 & 2 & 2 & Buruk \\
\hline & & 10.2 & 2 & 2 & 2 & 2 & 2 & Buruk \\
\hline & & 10.3 & 1 & 1 & 1 & 1 & 1 & $\begin{array}{l}\text { Buruk } \\
\text { Sekali }\end{array}$ \\
\hline
\end{tabular}


Tabel 5 Hasil Perhitungan Kesenjangan Keseluruhan Laboratorium Teknik Industri UNISBA

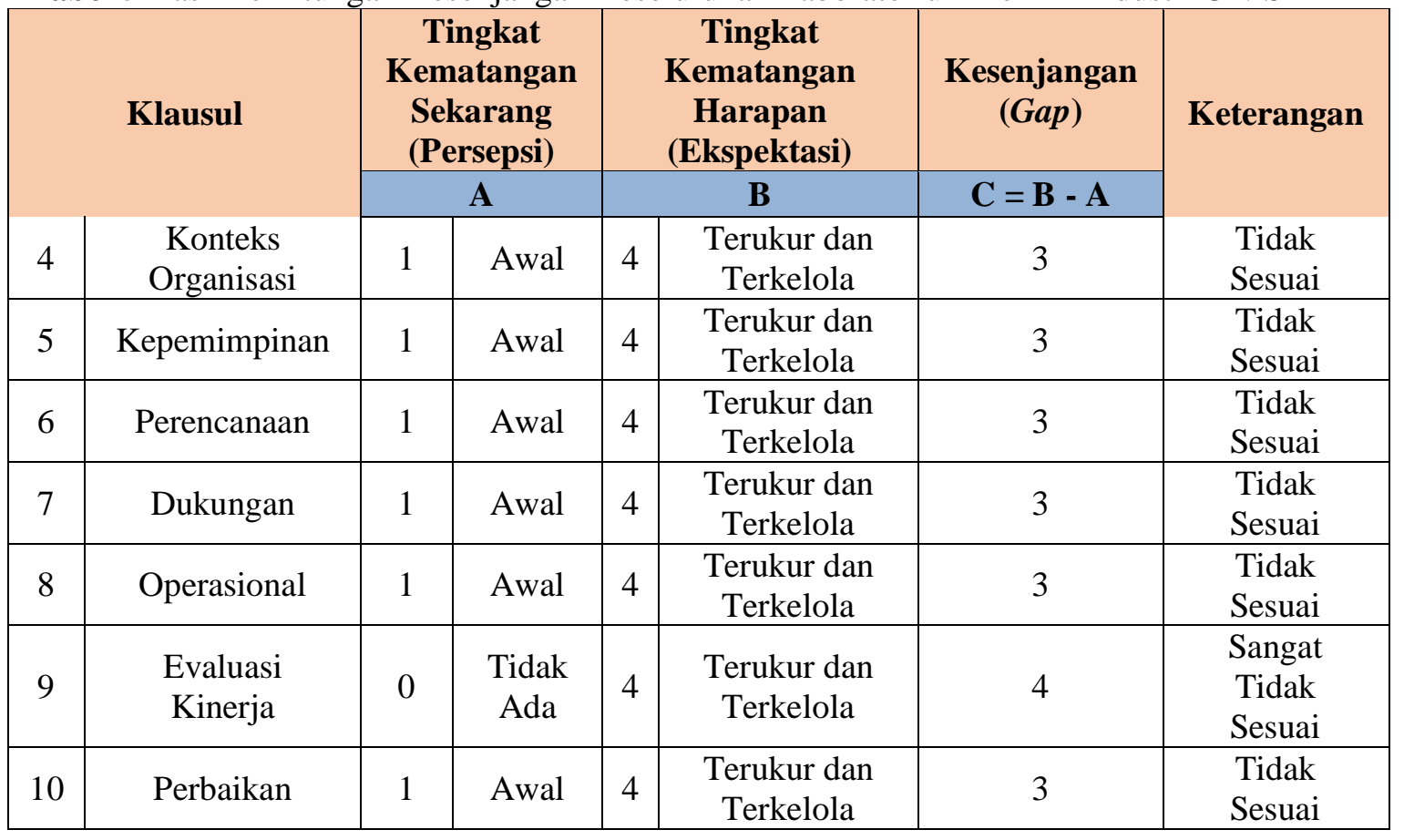

Berdasarkan Tabel 5 diatas dapat diketahui bahwa tingkat kematangan sekarang ke 7 klausul ini belum memenuhi atau tidak sesuai dengan tingkat kematangan harapan. Pada klausul $4,5,6,7,8$, dan 10 memiliki selisih 3 tingkat untuk mencapai target yang diharapkan sedangkan pada klausul 9 memiliki selisih 4 tingkat untuk mencapai target yang diharapkan. Oleh karena itu, berdasarkan hasil pengolahan kesenjangan menandakan bahwa laboratorium membutuhkan pengelolaan sistem manajemen mutu di laboratorium sehingga dapat mempermudah laboratorium dalam melakukan pengelolaannya.

Hasil yang didapatkan setelah melakukan berbagai proses pengolahan data yaitu seluruh Laboratorium masih belum menerapkan sistem manajemen mutu. Hal ini dikarenakan sistem manajemen mutu belum sampai pada ruang lingkup Laboratorium tetapi masih masuk dalam ruang lingkup program studi. Oleh karena itu dibutuhkan usulan kepada seluruh Laboratorium. Adapun Usulan yang diberikan menjadi 3 bagian yaitu:

\section{Usulan secara umum}

Berikut ini usulan yang diberikan secara umum sebagai berikut:

1. Seluruh Laboratorium harus menerapkan sistem manajemen mutu dengan menggunakan ISO 9001:2015. Hal ini bertujuan agar laboratorium tersebut dapat mempunyai standar sistem manajemen mutu yang berlaku di laboratorium dan dapat mengelola laboratorium secara baik dan benar.

2. Melakukan pelatihan tentang ISO 9001:2015 kepada kepala laboratorium, laboran, dan staf ahli Laboratorium. Pelatihan yang diberikan ini bertujuan agar laboratium dapat mengenal sistem manajemen mutu ISO 9001:2015 dan mengerti bagaimana menerapkan ISO 9001:2015 di laboratorium.

3. Melakukan evaluasi dan update secara terus menerus untuk aboratorium. Hal ini bertujuan agar laboratorium dapat mengikuti perkembangan dan mengevaluasi hasil yang dikerjaan dari laboratorium tersebut.

\section{Usulan kelengkapan dokumen}

Usulan dari sub bab ini yaitu usulan pada seluruh Laboratorium. Hasil yang didapatkan bahwa selain dari belum menerapkan sistem manajemen mutu, Laboratorium juga masih mempunyai beberapa dokumentasi yang kurang, belum lengkap, dan belum relevan dengan persyaratan yang 
dilakukan dengan identifikasi penyesuaian. Untuk itu diberikan usulan kelengkapan dokumen untuk setiap persyaratan dalam klausul ISO 9001:2015 dikarenakan terdapat dokumen yang belum lengkap dan relevan dengan persyaratan yang diberikan. Berikut ini adalah daftar usulan kelengkapan dokumen yang akan ditunjukkan pada Tabel 6 .

Tabel 6Usulan Dokumen untuk Kelengkapan Dokumen

\begin{tabular}{|c|l|}
\hline $\begin{array}{c}\text { Kode } \\
\text { Dokumen }\end{array}$ & \multicolumn{1}{c|}{ Nama Dokumen } \\
\hline A & Standar Standar Laboratorium \\
\hline B & Formulir Identifikasi Resiko dan Peluang \\
\hline C & Formulir Evaluasi Capaian Proses \\
\hline D & Formulir Monitoring Kinerja Laboratorium \\
\hline E & Formulir Rencana Pembelajaran Praktikum \\
\hline F & Formulir Pengecekan Peralatan Laboratorium \\
\hline G & Formulir Kalibrasi Alat Laboratorium \\
\hline H & Formulir Jadwal Pemeliharaan Alat Laboratorium \\
\hline I & Formulir Daftar Tamu Laboratorium \\
\hline J & Formulir Tempat Penitipan/Penyimpanan Barang Praktikan \\
\hline K & Formulir Evaluasi Asisten Oleh Praktikan \\
\hline L & Uraian Tugas Pekerja di Laboratorium \\
\hline M & $\begin{array}{l}\text { Standar Operasional Prosedur Kerja Laboratoriium } \\
\text { UNISBA }\end{array}$ \\
\hline
\end{tabular}

\section{Usulan standar operasional prosedur}

Usulan yang akan diberikan kepada seluruh Laboratorium. Usulan yang diberikan tersebut dalam bentuk Standar Operasional Prosedur (SOP). SOP yang diberikan ini berbentuk instruksi kerja dan alur dalam melaksanakan pelaksanaan praktikum di setiap laboratorium karena laboratorium belum mempunyai prosedur kerja dan agar dapat mempermudah para pekerja yang terdapat di laboratorium dalam menyesuaikan prosedur kerja. Adapun bentuk usulan SOP yang akan diberikan dapat dilihat di Dokumen M. Untuk daftar SOP yang dibuat yaitu sebagai berikut:

1. Standar Operasional Prosedur (SOP) Penerimaan Calon Asisten

2. Standar Operasional Prosedur (SOP) Pendaftaran Praktikum

3. Standar Operasional Prosedur (SOP) Perencanaan Praktikum

4. Standar Operasional Prosedur (SOP) Pelaksanaan Praktikum

5. Standar Operasional Prosedur (SOP) Evaluasi Praktikum

\section{Kesimpulan}

Berdasarkan pembahasan dalam penelitian ini, peneliti menyimpulkan beberapa hasil penelitian sebagai berikut:

1. Hasil pengumpulan data yang dilakukan menunjukkan bahwa sistem manajemen mutu saat ini di Laboratorium Teknik Industri Universitas Islam Bandung (LTI UNISBA) belum menerapkan ISO 9001:2015 dikarenakan penerapan yang dilakukan masih dalam ruang lingkup program studi dan belum masuk pada ruang lingkup laboratorium.

2. Hasil evaluasi yang telah dilakukan dengan metode tingkat kematangan pada LTI UNISBA menunjukkan bahwa nilai yang didapatkan sebesar 1,76. Nilai tersebut berada pada level 1 (awal) yang berarti laboratorium sudah mulai mengenali proses sistem manajemen mutu di laboratoriumnya, tidak terorganisasi, dilakukan secara individu dan belum ada standarisasi. Terdapat bukti bahwa laboratorium telah menyadari adanya masalah yang akan dihadapi. Pendekatan yang dilakukan secara keseluruhan belum terorganisasi.

3. Usulan yang diberikan kepada LTI UNISBA yaitu harus menerapkan ISO 9001:2015 untuk sistem manajemen mutu, melakukan pelatihan ISO 9001:2015, melengkapi 
dokumen-dokumen yang diperlukan, dan membuat standar operasional prosedur kerja.

4. Berdasarakan 7 prinsip ISO 9001:2015 yang harus diterapkan yaitu pada prinsip keputusan berbasis bukti (Evidence-Based Decision Making) dikarenakan pada laboratorium masih belum melengkapi dokumen yang dibutuhkan sehingga membutuhkan prinsip ini dalam penerapannya.

\section{Acknowledge}

Terima kasih kepada seluruh pihak yang terlibat dan memberi dukungan moril maupun material sehingga Tugas Akhir ini dapat diselesaikan sebagai syarat kelulusan memperoleh gelar Sarjana Teknik pada Program Studi Teknik Industri, Universitas Islam Bandung.

\section{Daftar Pustaka}

[1] Abuhav, I., 2017. ISO 9001:2015 A Complete Guide to Qualiy Management System. New York: CRC Press.

[2] Anggraeni, L. F., 2017. Evaluasi Manajemen Mutu Berdasarkan ISO 9001: 2015 pada PT Qasico Technology Indonesia. Doctoral dissertation.

[3] Hamta, H., 2014. Analisis Kepuasan Perusahaan Terhadap Kualitas Pelayanan Security PT. Cakra Garda Nusantara Di PT. Rifansi Dwi Putra. Doctoral dissertation, Universitas Islam Negeri Sultan Syarif Kasim Riau.

[4] ITGI, 2007. Governance institute. About IT Governance Framework: Information Systems Audit and Control Foundation. 4 ed. Rolling Meadows: ISACA.

[5] Philips, A. W., 2015. ISO 9001:2015 internal audits made easy : tools, techniques, and step by step. 4 ed. Milwaukee: Quality Press.

[6] Widia, N., 2012. Pengukuran Maturity Level E-Learning. Seminar Nasional Teknologi Informasi Komunikasi dan Industri. 